\title{
LIMITES E CONTRIBUICCÕES DA EDUCAÇÃO PARA A FORMAÇÃO DE TRABALHADORES
}

LIMITS AND CONTRIBUTIONS OF EDUCATION TO WORKER FORMATION

LÍMITES Y CONTRIBUCIONES DE LA EDUCACIÓN A LA FORMACIÓN DE LOS TRABAJADORES

Celso João Ferretti ${ }^{1}$

\begin{abstract}
RESUMO
Por meio do presente artigo pretende-se examinar os processos de formação a que são submetidos membros da classe trabalhadora partindo-se do pressuposto que estes não se esgotam na educação escolar. Com esse objetivo são discutidas as transformações de caráter neoliberal pelas quais passou o capitalismo tendo em vista o enfrentamento da crise da década de 1970, considerando que estas promoveram alterações na formação profissional dos trabalhadores bem como na estrutura do emprego e na constituição/composição da classe trabalhadora originária da organização taylorista-fordista do trabalho. Hoje tal classe, não apenas no Brasil, mas também no plano internacional, é constituída majoritariamente pelos trabalhadores de serviços e se caracteriza por sua complexidade e heterogeneidade, assim como pelo enfraquecimento de sua participação sindical e de suas ações coletivas de natureza política. Os próprios sindicatos foram profundamente afetados. Nessa nova configuração instituem-se processos formativos adequados à organização flexível das empresas, as quais investem pesadamente na subjetividade dos trabalhadores, processos esses que encontram eco na sociabilidade de caráter neoliberal e, inclusive, nas propostas educacionais que a valorizam. Defende-se que, contrariamente a estas, seja fortalecida a concepção gramsciana de formação integral, mas, também que, para tal fim, a educação se articule com outras agências sociais.
\end{abstract}

Palavras-chave: Formação do trabalhador. Classe trabalhadora século XXI. Sindicalização.

\begin{abstract}
This article intends to examine the processes of formation to which members of the working class are subjected, assuming that they do not exhaust themselves in school education. With this objective, the neoliberal transformation that capitalism underwent in order to cope with the crisis of the 1970s are discussed, considering that they promoted changes in the professional formation of workers as well as in the structure of employment and in the constitution/composition of the working class from the Taylorist-Fordist organization of labor. Today, such a class, not only in Brazil, but also internationally, is made up mostly of service workers and is characterized by its complexity and heterogeneity, as well as the weakening of its union participation and its collective political actions. The unions themselves were deeply affected. In this new configuration, formative processes are instituted adapted to the flexible enterprise organization, which invest heavily in the workers' subjectivity, processes that are echoed in the neoliberal sociability and even in the educational proposals that value it. It is argued that, contrary to these, the Gramscian conception of integral formation is strengthened, but also that, to this end, education articulates with other social agencies.
\end{abstract}

Keywords: Worker formation. 21st century working class. Unionization.

\section{RESUMEN}

Este artículo pretende examinar los procesos de formación a los que están sujetos los miembros de la clase trabajadora, suponiendo que no se agoten en la educación escolar. Con esta finalidad, se discuten las transformaciones neoliberales que sufrió el capitalismo para hacer frente a la crisis de la década de 1970, considerando que promovieron cambios en la formación profesional de los trabajadores, así como en la 1 Centro de Estudos Educação e Sociedade (CEDES). Vargem Grande Paulista - SP, Brasil. ORCID: https://orcid.org/0000-0002-86920398. E-mail: celsojoaoferretti@gmail.com

Artigo recebido em setembro de 2019. Aprovado em novembro de 2019. 
estructura del empleo y en la constitución/composición de la clase que tiene origen en la organización de trabajo taylorista-fordista. Hoy, tal clase, no solo en Brasil, sino también internacionalmente, está compuesta principalmente por trabajadores de servicios y se caracteriza por su complejidad y heterogeneidad, así como por el debilitamiento de su participación sindical y sus acciones políticas colectivas. Los propios sindicatos se vieron profundamente afectados. En esta nueva configuración, se instituyen procesos de capacitación apropiados para la organización flexible de las empresas, que invierten mucho en la subjetividad de los trabajadores, procesos que se hacen eco en la sociabilidad neoliberal e incluso en propuestas educativas que lo valoran. Se argumenta que, contrariamente a esto, se fortalece la concepción gramsciana de la formación integral, pero también que, para este fin, la educación sea articulada con otras agencias sociales.

Palabras clave: Capacitación laboral. Clase obrera del siglo XXI. Sindicalización.

\section{Introdução}

É inegável que a educação escolar desempenha papel de relevo na formação de crianças e jovens tendo em vista, não apenas sua participação nas atividades de trabalho, mas, também, na sua constituição como cidadãos, aos quais cabe praticar o exercício crítico da atividade profissional, assim como dos efeitos que sobre ela são exercidos por políticas econômicas e sociais. Tal relevo depende, evidentemente, da qualidade da educação escolar fornecida a tais crianças e jovens. Do nosso ponto de vista tal qualidade, por sua vez, depende, fundamentalmente, do acesso desse público a conhecimentos significativos historicamente produzidos pela interação entre os seres humanos e a natureza, bem como entre si, nesse processo. A tal questão se retornará em outro momento.

Por ora cabe examinar as limitações da educação escolar tendo em vista a formação do trabalhador e as relações entre esta e a luta de classes. Nesse sentido, parece-nos necessário ponderar sobre os significados que atribuímos ao termo formação. De acordo com o dicionário Houaiss (2001), a formação refere-se, genericamente, "ao ato, efeito ou modo de constituir (algo), criação, construção, constituição". Nessa perspectiva, a definição sugere ação ou ações intencionais no sentido de contribuir para formar alguém. Embora essa ilação não seja falsa, deve-se considerar, no caso da formação de seres humanos, que esta decorre

não apenas da intencionalidade de quem se disponha a produzi-la, mas, também, de circunstâncias não planejadas ou não desencadeadas diretamente com essa finalidade, como sugere uma segunda acepção do termo formação: "maneira como uma pessoa é criada, tudo que lhe molda o caráter, a personalidade" (HOUAISS; VILLAR, 2001).

A formação de uma pessoa, neste caso de um trabalhador, ou conjunto deles, resulta, assim, em grande parte dos processos de socialização que ocorrem durante sua vida pessoal e profissional. Numa perspectiva mais precisa, esta acepção pode ser encarada como um aspecto do processo mais amplo de constituição ontológica do ser social, cujas origens e desenvolvimento remontam, na perspectiva lukcasiana, ao trabalho por meio do qual o homem se constitui como ser genérico, no processo de submeter a natureza a seus desígnios, tendo em vista sua reprodução.

Assim, a escolarização, independentemente de sua qualidade, não é suficiente para caracterizar o processo formativo pelo qual passa o trabalhador na longa trajetória de sua constituição como sujeito social e, nessa condição, como partícipe de atividades profissionais, ainda que estas possam, em determinado momento dessa trajetória, ser objeto de preocupação de tal formação específica. Dito de outra forma, a formação do trabalhador implica ações e movimentos que extrapolam o campo educacional, situandose no plano da estruturação do trabalho no âmbito do capitalismo contemporâneo e nas medidas e decisões tomadas no campo da politica vis-a-vis tal estruturação.

Podemos dizer, assim, que a formação do trabalhador, orientada ou não, à sua participação em lutas de classe, implica a própria vivência da sua condição de trabalhador. Nesse sentido, a vivência da condição de trabalhador é parte integrante de seu processo 
de formação e se dá pela atuação de outros agentes formativos que não a escola. Tais agentes podem referendar elementos presentes na formação escolar, bem como negálos ou questioná-los. A(s) empresa(s) em que esse trabalhador venha a atuar pode $(\mathrm{m})$, por exemplo, tomar como referência para mantê-lo empregado, a submissão e não a autonomia que a educação escolar tenha, porventura, enfatizado. Ou, ao contrário, dar relevo à autonomia, diferentemente da submissão que a agência escolar possa ter privilegiado. Ou, ainda, reformular, à sua feição, tanto uma quanto outra, além da possível formação profissional específica que a escola possa ter oferecido. O mesmo pode ser dito a respeito da importância conferida às posturas que valorizam o coletivo ou o individualismo.

Cabe, neste caso, estabelecer a distinção entre processos formativos que a empresa desenvolve tendo em vista moldar o trabalhador às suas características (treinamentos, seminários, estágios, etc) e, por outro lado, o processo de formação que decorre não de ações intencionais da empresa que o contrata, como as indicadas, mas da própria forma da empresa se organiza para produzir ou fazer circular mercadorias. Uma empresa estruturada segundo a perspectiva taylorista/fordista tem certas características que, por si só, exigem ou induzem à aquisição ou desenvolvimento de certos conhecimentos, destrezas, formas de comportamento e subjetividade compatíveis com tal estrutura. Outra, estruturada da perspectiva da acumulação flexível pode demandar tais características, mas com configurações muito diversas, ou ainda, novas características. Dito de outra forma, o processo de socialização profissional em que o trabalhador se envolve ou é envolvido faz parte do seu processo de formação, o qual pode contrapor-se ou referendar elementos presentes na formação escolar. É bem provável, assim, que tanto a formação escolar quanto a decorrente das condições específicas do trabalho estejam presentes, de forma contraditória e dialética, durante a vida profissional do trabalhador, entendendo esta, na presente conjuntura econômica e política do Brasil, como composta por experiências de emprego e desemprego e, especificamente, de precarização.

Parece-me importante destacar esse aspecto para adentrar a discussão da luta de classes, posto que a classe trabalhadora é composta pelos sujeitos que passaram, de alguma forma, pelos processos de formação acima referidos.

Necessário indagar, portanto, como se constitui hoje a classe trabalhadora, posto que, mesmo partindo das concepções marxianas a respeito, não podemos, no meu entender, conceber as classes em disputa, hoje, da mesma forma que no século XIX, ou mesmo durante boa parte do século XX. Ainda que a forma capitalista de produção prevaleça, encontra-se bastante modificada em relação àquele momento, por conta das próprias contradições e crises que enfrentou no decorrer do século $X X$ e vem enfrentando nestes vinte anos do século XXI. Isto não significa negar, todavia, a disputa entre as classes fundamentais: burguesia e proletariado.

\section{A restruturação produtiva e a formação do trabalhador}

Cumpre, portanto, examinar, ainda que resumidamente, as consequências que se operaram no âmbito do trabalho a partir do processo de "reestruturação produtiva" tendo em vista o avanço de tecnologias de base física e de gestão, bem como os processos de flexibilização da produção promovidos para fazer frente às crises do capitalismo após os "30 anos gloriosos" (1945-1975). Parte-se do pressuposto de que tal processo, não só pelas razões de ordem econômica, mas, também, pelas de ordem político-ideológica, determinou mudanças expressivas na configuração dos trabalhadores e de sua classe em nível mundial.

A denominada "reestruturação produtiva" refere-se, na verdade, a algo mais complexo que a própria produção na medida em que é parte de um processo socioeconômico e político mais amplo, o qual remete suas origens à crise estrutural capitalista da década de 1970. Tal crise deveu-se a vários fatores, os quais atuaram 
conjuntamente na sua produção, a saber, a queda da taxa de lucro, promovida pelo maior valor do fator trabalho, a crise da organização taylorista-fordista da produção, certa autonomização do capital financeiro em relação ao industrial, a "fusão entre empresas monopolistas e oligopolistas", a "crise do Estado do bem-estar social" e o "incremento acentuado das privatizações (...) [e das] flexibilizações do processo produtivo, dos mercados e da força de trabalho" (ANTUNES, 1999, p. 29-30).

O enfrentamento da crise pelo capital deu-se a partir das teses defendidas pelo neoliberalismo. Embora estas tenham sido teoricamente desenvolvidas por Hayek e por Friedman em plena vigência do Estado de Bem Estar Social nos EEUU, seus desdobramentos efetivos em termos de mudanças nas relações entre o estado e o capital, particularmente no que concerne à produção industrial, só se fizeram sentir a partir da crise acima referida.

O neoliberalismo, como expressão da reorganização político-ideológica da dominação do Capital, provocou a revisão das relações entre este e o Estado assentadas sobre o keynesianismo. Isso implicou na minimização do Estado por meio da diminuição de seu setor produtivo, pela indução de parcerias com agências privadas e pela desregulamentação de direitos do trabalho. Por outro lado, o neoliberalismo provocou tanto processos de desindustrialização quanto o expansão dos capitais financeiros. Tais alterações favoreceram principalmente os países capitalistas avançados, os quais reuniam as condições necessárias para a implementação das transformações visadas como possibilidades de enfrentamento da crise. Porém tanto estes quanto os países cuja industrialização era menos desenvolvida enfrentaram as consequências da crise, as quais foram, todavia, mais duras para os segundos em termos de desemprego, da precarização do trabalho e da agressão ambiental.

Embora a crise estrutural do capital tivesse determinações que ultrapassavam a esfera da produção propriamente dita, seu enfrentamento reduziu-se à reestruturação do taylorismo-fordismo, deixando intocados os fundamentos do próprio capital. Tal reestruturação, porém, não se circunscreveu às novas formas de organização do trabalho produtivo e ao emprego de novas tecnologias. Aproveitou também o aprendizado que os empresários desenvolveram a respeito da capacidade dos operários de pensar sobre seu próprio trabalho como haviam demonstrado nas lutas travadas contra a organização taylorista-fordista da produção, dando-se conta de que poderiam utilizar tal capacidade a seu favor.

Dessa perspectiva, o Capital agiu sobre os processos produtivos e sobre a gestão organizacional, promovendo sua reestruturação com o objetivo de recuperar os níveis anteriores de expansão e acumulação. A organização taylorista/fordista do trabalho fabril não desapareceu de todo, pois internamente a muitas empresas que a adotavam deu-se uma espécie de convivência simbiótica entre ela e as medidas relativas à reestruturação, bem como houve, conforme Harvey (1992), articulações que combinaram, por meio de subcontratação, processos produtivos promotores da relação estre as empresas de características fordistas e outras que passaram a utilizar formas de produção flexíveis, caracterizando um processo de desconcentração produtiva e, ao mesmo tempo, a redução de jornadas, o que resultou, de um lado, na intensificação e precarização do trabalho dos que conseguiram manter-se empregados e, de outro, em desemprego e terceirização. ${ }^{2}$

Tais processos fizeram uso, na produção, dos avanços tecnológicos produzidos na década de 1980 tendo por referência a passagem da produção assentada na tecnologia de base eletromecânica para as de natureza micro eletrônica, com apoio na automação, na robótica e na informática, os quais viabilizam, do ponto de vista tecnológico, a flexibilização da produção. Além disso, alteraram, por meio da gestão organizacional, o controle dos tempos e movimentos dos trabalhadores, a distribuição física destes

\footnotetext{
2 De acordo com Harvey (2011, p. 59), "a disponibilidade de reservas de trabalho maciças (inclusive aquelas com alto nível de educação, cada vez mais na Índia e no Sudeste Asiático) em todo o mundo é inegável, e pesa sobre os níveis da luta de classes, com uma vantagem poderosa para o capital".
} 
nas fábricas (da linha de montagem para as equipes de trabalho), as características das formas de produzir (da produção em massa para a parcelarizada), promovendo a valorização do individualismo e da competição no plano subjetivo, ainda que fazendo o discurso da cooperação.

Entre os países que promoveram as experiências de flexibilização, as desenvolvidas pelo Japão a partir das fábricas da Toyota foram as que causaram maior impacto, seja pelo desenvolvimento tecnológico que estimularam na indústria japonesa, seja por sua propagação em escala mundial, a ponto de a acumulação flexível ser continuamente identificada com o toyotismo ou com o denominado modelo japonês. Esse modelo inverte o processo taylorista-fordista. Nele a produção é iniciada a partir da demanda do cliente, portanto individualizada, valendo-se do just in time e do kanban, dois procedimentos que, pelas suas características, permitem acelerar e flexibilizar a fabricação, reduzindo o tempo gasto, o que acarreta três benefícios: diminuição de custos, rápido retorno dos valores empregados na produção, ${ }^{3}$ e diminuição no número de trabalhadores envolvidos, ao mesmo tempo que implicam a capacidade de atender demandas pequenas e variadas dos clientes. A utilização de ambos os procedimentos exige que os trabalhadores trabalhem em equipe, operando simultaneamente, cada um de seus membros, mais de uma máquina ao mesmo tempo, o que conduz, de um lado, à concepção de trabalhador polivalente ${ }^{4} \mathrm{e}$, de outro, ao aumento da velocidade da produção e, portanto da exploração do trabalho humano. Além disso, o toyotismo otimizou a capacidade imaginativa e criadora dos operários, enfim, seu senso crítico funcional, o que foi percebido pelos capitalistas, como já apontado, criando os Círculos de Controle de Qualidade, por meio dos quais os trabalhadores são estimulados a oferecer contribuições para melhorar a qualidade e a produtividade, ou em outros termos, colocar sua subjetividade a serviço de tal produtividade.

Outro elemento diferenciador entre o taylorismo-fordismo e a organização flexível reside no tipo de integração presente em cada uma. No primeiro caso predominava a integração vertical entre as áreas de produção. No segundo, dá-se a integração horizontal a qual permite que a empresa se volte para os aspectos centrais de sua atividade principal, delegando às subcontratadas a produção de elementos básicos para a constituição do produto. Isto implica que o just in time, assim como o kanban são utilizados, além de no âmbito da empres- mãe, na relação entre esta e as subcontratadas, o que estende a flexibilização para o exterior desta, contribuindo para a propagação e generalização desses métodos.

Há também a considerar, no caso japonês, outro elemento que foi levado em conta para produzir o modelo. A Toyota e outras montadoras japonesas envolveramse, na década de 1950, em disputas acirradas com o sindicalismo praticado no país, tendo em vista suas reivindicações "contra a racionalização do trabalho e por aumentos salariais". As batalhas foram vencidas pelo patronato que, a partir delas, criou "o que se constituiu no traço distintivo do sindicalismo japonês da era toyotista: o sindicalismo de empresa, o sindicato-casa, atado ao ideário e ao universo patronal" (ANTUNES, 1995, p. 25) O aperfeiçoamento posterior desse tipo de sindicato em outro ainda mais controlador, fazendo uso combinado de repressão e cooptação, inclusive da subjetividade dos trabalhadores, resultou na transformação da Toyota numa família, da qual faziam parte os que nela atuavam. Neste tipo de organização sindical, adotada por grandes empresas japonesas, a subordinação ao patronato era recompensada com "a obtenção de emprego vitalício para uma parcela dos trabalhadores", com "ganhos salarias decorrentes da produtividade" (ANTUNES, 1995, p. 25) e acesso a funções de responsabilidade na empresa, constituindo o que Antunes denomina de "sindicalismo

\footnotetext{
O just in time é um procedimento organizativo que estipula que qualquer compra, transporte ou produção deve ser feito na hora certa. 0 kanban é também um procedimento organizativo que consiste na marcação das etapas de uma dada produção utilizando marcadores ou sinalizadores. Usualmente os dois procedimentos são utilizados em conjunto com o objetivo de economia de tempo na produção.

${ }^{4} \mathrm{O}$ fato de um trabalhador operar simultaneamente várias máquinas não significa que ele seja, necessariamente, polivalente, mas, sim, multifuncional. A polivalência implica mais do que a capacidade acima referida. Segundo a perspectiva da flexibilização, implica na capacidade do trabalhador mobilizar diferentes competências tendo em vista a busca de solução para um problema ou a criação de uma concepção, um método, um procedimento de trabalho, etc.
} 
de envolvimento", o qual acirra a subordinação dos trabalhadores a ela. Essa estrutura favorece a preservação, pela empresa, de seus quadros mais qualificados ao mesmo tempo em que viabiliza a ampliação do número de trabalhadores de tempo parcial e dos temporários, bem como a terceirização interna e externa da produção. Ou seja, enquanto qualifica os trabalhadores mais afinados com a empresa, precariza o trabalho dos demais. A flexibilização no plano da produção ampliou-se, posteriormente, não apenas para as subcontratadas, mas, também para as agências prestadoras de serviços para o setor produtivo.

Tais mudanças significaram, de um lado, ganhos para o capital em relação à organização taylorista-fordista no que tange à melhor qualificação profissional dos trabalhadores. No entanto, observou-se, também, que elas tenderam a favorecer mais o capital que o trabalho, além de promover a intensificação deste e a não observância de direitos trabalhistas.

Acresce-se, às criticas acima, a "falácia da qualidade total" defendida pelas empresas flexibilizadas quando esta é confrontada com o valor de uso das mercadorias. De acordo com Antunes (1999, p. 50), "torna-se evidente [que] quanto mais "qualidade total' os produtos devem ter, menor deve ser seu tempo de duração". O argumento é o de que a diminuição da vida útil dos produtos, por meio da promoção da obsolescência programada, visa "aumentar a velocidade do circuito produtivo (...) [de] modo a ampliar a velocidade de produção de valores de troca" (ANTUNES, 1999, p. 50) o que, segundo o autor, contribui para a não preservação do valor de uso e para a degradação do meio ambiente.

Os processos de flexibilização da produção anteriormente referidos afetaram, de várias formas, a classe trabalhadora, questão a ser abordada na sequência. Serão objeto de consideração tanto as transformações referentes às formas de contratação, assalariamento e oferta de emprego, ou seja, a materialidade da classe trabalhadora, quanto à subjetividade de seus componentes.

\section{A materialidade da classe trabalhadora}

No que se refere ao primeiro aspecto verificou-se que mudanças introduzidas pelo neoliberalismo na produção, na década de 1990, promoveram, simultaneamente, tanto o processo de desindustrialização quanto o crescimento significativo do setor serviços, o qual, inclusive, acabou por incorporar contingentes oriundos do setor produtivo que haviam perdido seus empregos. Nessa linha, Pochmann e Moraes (2017, p. 98) avaliam que, "no final do século XX, tal realidade evidenciava um indicador claro: quase $80 \%$ das novas vagas estavam no setor terciário. E dois terços das novas ocupações eram criadas em estabelecimentos de menos de dez empregados". ${ }^{5}$

Tais condições criaram o terreno propício para que a classe trabalhadora se tornasse mais heterogênea e mais complexa do que aquela existente sob o taylorismo-fordismo, ao mesmo tempo em que instituíram processos de individualização e competição entre seus componentes não observados anteriormente sob aquela organização.

Para dar conta dessa complexidade e heterogeneidade Antunes utiliza a expressão "classe-que-vive-do-trabalho". Seu "primeiro objetivo [é] conferir validade contemporânea ao conceito marxiano de classe trabalhadora" (1999, p, 101) e, nesse sentido "apreender sua efetividade e concretude" por contraposição a autores que, frente à reestruturação produtiva, referiram-se a ela como tendente a promover o fim do trabalho e, por isso, das classes sociais. Dado o caráter polêmico que a concepção

\footnotetext{
A situação apresentada pelos autores é expressão de um problema de maior amplitude. De acordo com Fagiani e Previtali (p. 58) "só nos Estados Unidos houve redução da classe trabalhadora nas indústrias da ordem de $35 \%$ no período 1990 a 2010 " e também no mesmo país, "entre 2000 e 2012, as taxas de sindicalização foram reduzidas em 2,4\%" (p. 59). A Folha de São Paulo de 02/08/2019 aponta para o intenso processo de desindustrialização ocorrido no Brasil, em particular a partir da crise mundial de 2008. Deve-se considerar, ainda, que várias empresas que atuam no setor serviços operam utilizando tecnologia digital e robôs visando agilizar os processos de oferta de suas atividades. Isto significa que trabalhadores excluídos do setor produtivo que migram para o setor serviços podem encontrar dificuldades de se empregarem de forma permanente também nessa esfera.
} 
assume, pela amplitude de que se reveste, considero desejável valer-me das palavras do autor para explicitá-la.

Da perspectiva deste, a classe trabalhadora, tal como se configura na atualidade, é constituída pela "totalidade dos que vendem sua força de trabalho, tendo como núcleo central os trabalhadores produtivos (no sentido dado por Marx, especialmente no Capítulo VI, Inédito)", representados, estes, pelo proletariado industrial (ANTUNES,1999, p. 103). A noção inclui também o proletariado rural. Dessa perspectiva, segundo Antunes, "o trabalho produtivo (...) não se restringe ao trabalho manual direto (...) incorporando também formas de trabalho que são produtivas, que produzem mais valia, mas que não são diretamente manuais." (p. 102) ${ }^{6}$. Para ele, "a classe-que-vive-do-trabalho engloba também os trabalhadores improdutivos, aqueles cujas formas de trabalho são utilizadas como serviço", ou seja, que atuam "no setor de serviços, bancos, comércio, turismo, serviços públicos [ou] que realizam atividades nas fábricas, mas não criam diretamente valor." (p.102), bem como "o subproletariado moderno, part time, (...) os trabalhadores terceirizados e precarizados, os trabalhadores assalariados da chamada "economia informal" (...) além dos trabalhadores desempregados (...) (p. 103) ${ }^{7}$

As mudanças introduzidas pela organização do trabalho de cunho neoliberal não apenas produziram na classe trabalhadora as alterações anteriormente referidas como também produziram internamente a esta uma divisão ausente ou pouco presente na organização taylorista-fordista, qual seja, o incremento significativo da mão de obra feminina, especialmente no trabalho part time submetido à precarização e à desregulamentação (ANTUNES, 1999, p. 105). Essa participação maior das mulheres se dá por meio de processos que, se de um lado lhes é favorável, permitindo sua presença mais efetiva no mercado, de outro, as prejudicam dado que lhes são destinados, nos processo de produção, tarefas ou atividades menos complexas, enquanto aos homens são reservados os postos em que predominam as atividades de concepção, melhor remunerados, situação que, por extensão, implica diferenças nos processos de qualificação a que são submetidos. Elas são, também, menos consultadas quando adotados procedimentos de gestão participativa. Por outro lado, os sindicatos têm se mostrado menos propensos a incluir mulheres em seus quadros, assim como trabalhadores parcelares. ${ }^{8}$

Dada sua complexidade e heterogeneidade a classe trabalhadora atual encontra muito mais dificuldades para estruturar-se tendo em vista os enfrentamentos das circunstâncias adversas que as novas formas de organização do trabalho lhes antepõem. Isso decorre do fato de que

os organismos sindicais internacionais existentes no mundo contemporâneo têm quase sempre uma estruturação tradicional, burocrática e bastante institucionalizada [assumindo] uma pauta defensiva ou que se subordina à lógica do capital, opondo-se apenas a algumas de suas consequências mais nefastas. (ANTUNES, 1999, p. 116)

Reportando-se à situação nacional, relativamente a esse aspecto, Antunes aponta que na década de 1980 o sindicalismo brasileiro afirmou-se como movimento social dos trabalhadores, com forte caráter de classe contrariamente ao que se observava nos países capitalistas mais avançados, constituindo o que Pochmann e Moraes denominam de novo sindicalismo. A partir da década de 1990, os sindicatos nacionais, inclusive a combativa CUT da década anterior, passam a adotar o sindicalismo de colaboração, em função da adesão do país às concepções e políticas neoliberais, assim como o fez a Força Sindical, no rastro dos sindicatos de outros países, numa postura defensiva

\footnotetext{
O texto não explicita o sentido da expressão não (...) diretamente manuais. Talvez Antunes esteja se referindo ao trabalho de caráter imaterial de natureza produtiva.

Conforme Pochmann e Moraes (2017, p. 51), "grande parte desses novos trabalhadores está conectada cada vez mais numa rede complicada de fornecedores de serviços 'independentes' e subcontratados, agências de temporários, sistemas de franquias. São formas de contratar que (...) os torna cada vez mais precários e vulneráveis."

8 Harvey $(2011$, p. 57) é mais enfático a respeito. De acordo com ele "a força de trabalho potencial tem gênero, raça, etnia e tribo e se divide pela língua, política, orientação sexual e crença religiosa", diferenciação utilizada pelo capital para administrar a oferta de força de trabalho, valendo-se, inclusive, de distinções internas a ela relativamente a essas diferenças.
} 
em relação aos avanços de tais concepções e políticas. Os resultados obtidos foram precários. $^{9}$

No entanto, Antunes chama a atenção para o fato de que, no âmbito dessa Central preservaram-se, durante a década de 1990, apesar das dificuldades existentes, sindicatos que adotaram posturas de natureza socialista e anticapitalista. As alternativas de oposição que essa parcela da CUT apresentava ao sindicalismo brasileiro, no final do século XX defrontaram-se, no século seguinte, com dificuldades para afirmar-se como ação sindical anticapitalista, seja em função das políticas de compromisso marcadas pelo neoliberalismo de terceira via dos governos Lula e Dilma, seja, antes e após o golpe de 2016, com o avanço das forças de direita e com o recrudescimento das políticas de cunho neoliberal.

Ao contrário, tais políticas tenderam a fortalecer-se desde o ilegítimo governo Temer e ainda mais sob o governo Bolsonaro. São exemplares, nesse sentido, a PEC 95 que congelou, por vinte anos, recursos voltados para políticas sociais, bem como a reforma trabalhista que adequou a legislação respectiva ao figurino de flexibilização neoliberal. ${ }^{10}$

A leitura que Pochmann e Moraes realizam a respeito da organização dos trabalhadores que atuam no setor serviços sugere o acirramento da precariedade de tal organização. Para eles

O esvaziamento do padrão fordista de regulação do trabalho concomitante com o avanço das ocupações de serviços no Brasil aponta para um padrão híbrido de organização e lutas dos trabalhadores ${ }^{11}$. Cada vez mais, a nova classe trabalhadora de serviços torna-se exposta aos experimentos do uberismo na organização e remuneração da força de trabalho, o que faz com que a regularidade do assalariamento formal e a garantia dos direitos sociais e trabalhistas tendam a se reduzir drasticamente. (Pochmann e Moraes, 2017, p.100)

Em tais circunstâncias,

os sindicatos ficam fora da negociação coletiva e com mais restrição ao acesso à regulação pública do trabalho (direitos sociais e trabalhistas). Assim, o esvaziamento da organização se generaliza pela fragmentação da própria base social e territorial. Ao depender cada vez mais do rendimento diretamente recebido, sem a presença do histórico salário indireto (férias, feriado, previdência etc.), as greves dos trabalhadores tendem a seguir o padrão demarcado pela espontaneidade e horizontalidade nas relações de trabalho, o que pode valorizar o retorno de ideais que se assemelham ao velho anarquismo. (Pochmann e Moraes, 2017, p.101)

Dessa forma, a tendência entre os trabalhadores dos serviços é a de afastaremse dos sindicatos tradicionais e a buscar outras formas de associação que denominam "sindicalismo-movimento social" que não tem por referência a

empresa (fabril ou comercial), mas [o] terreno da moradia - o "barrio", a neighborhood, o gueto. Surgem como movimentos por direitos civis [e] manifestam-se por meios diferentes - passeatas, ocupação de prédios e praças públicas. Criam worker centers que são uma mistura de local de reunião, centro de serviços de apoio mútuo, centros

\footnotetext{
É necessário considerar que Gramsci (1978, p. 49), ao discutir o conceito de "relações de força" pondera que as ações desenvolvidas pelos sindicatos tendem, pelo seu grau de homogeneidade, de auto-consciência e de organização, a se identificar com o momentos de consciência política correspondente ao econômico-corporativo.

10 Em abril de 2019 o governo Bolsonaro emitiu a Medida Provisória da Liberdade Econômica (MP 881). Ela tramita no Congresso sob a denominação de Projeto de Lei de Conversão (PLV 17/2019). Na forma atual aprofunda a reforma trabalhista promovida pelo governo Temer e coloca em risco determinações legais contidas na CLT, em prejuízo dos trabalhadores. A aprovação do PLV implicará não apenas supressão de direitos dos trabalhadores, mas contribuição, também, para a fragmentação da classe trabalhadora por meio das formas de contratação nele previstas, enfraquecendo seu poder de reivindicação.

11 O hibridismo diz respeito, no entender dos autores, a articulação de formas de luta herdadas do novo sindicalismo que organizava os operários das indústrias fordistas com as formas de representação desenvolvidas pelos trabalhadores dos serviços.
} 
de cultura. Aqui e ali, firmam acordos com sindicatos tradicionais, quando estes se abrem à iniciativa. (Pochmann e Moraes, 2017, p. 105)

\section{A subjetividade dos trabalhadores}

O tema não é novo nas ponderações teóricas sobre o trabalho. Na literatura de origem marxista a discussão sobre a subjetividade do trabalhador é desenvolvida a partir das relações entre este e o trabalho que realiza sob a forma capitalista de produção, ou seja, o trabalho efetuado tendo como finalidade não o valor de uso, mas o valor de troca dos objetos produzidos. Dessa perspectiva, o trabalho realizado pelo ser humano teria, na melhor das hipóteses, natureza contraditória: é forma de este se constituir como ser humano, de acordo com a concepção ontológica do trabalho e, ao mesmo tempo, como ser que não se reconhece nem nos produtos que fabrica, nem na atividade de fabricação, nem em sua própria individualidade. Ou seja, como negação de si enquanto produto de seu próprio trabalho, na perspectiva ontológica. Sendo tal negação própria do trabalho sob o capitalismo, o que se verifica é a variação que ela assume frente às modificações que a forma capitalista de produção enceta tendo em vista as crises que enfrenta, criando para tal, conhecimentos científicos e tecnológicos de diversa natureza cujo objetivo é não apenas a superação de tais crises, mas, por meio desta alçar sua capacidade produtiva a uma etapa mais avançada. Nesse sentido, a subjetividade do trabalhador é permanentemente, mas ao mesmo tempo, diferenciadamente, subjugada pelos objetivos finais da produção. Dessa perspectiva é possível entender tanto o taylorismofordismo quanto as formas toyotistas de estruturação da produção e o crescimento das atividades de serviços como expressões do processo histórico do desenvolvimento capitalista e, necessariamente, de exploração do trabalho humano e sequestro de sua subjetividade. Da mesma forma, as mudanças ocorridas nas concepções a respeito da subjetividade do trabalhador podem ser interpretadas como adequação desta às transformações que o capitalismo produz sobre si mesmo. Não se trata, todavia, de um processo "natural", mas politica, social", cultural e economicamente produzido pelo capital tendo em vista a resolução de suas crises e o objetivo da continua acumulação.

O que há de notável, sob o neoliberalismo, é a mudança da imposição explícita de determinadas formas de subjugação da subjetividade do trabalhador por outras, pactuadas com ele. No taylorismo-fordismo predominavam as primeiras, ainda que temperadas, a partir da década de 1930, com as propostas da Escola de Relações Humanas ou Teoria das Relações Humanas. Esta se propôs rever as teorias clássicas de administração, nas quais se baseava Taylor, tendo em vista sua "humanização", com apoio principalmente na Psicologia Industrial e com o objetivo de aumentar, por meio da cooperação, a produtividade dos trabalhadores. A alegação era a de que para tal não bastava, como queria Taylor, ter o trabalhador certo no lugar certo sendo necessário considera-lo como ser social, levando em conta suas necessidades e motivações, bem como a dimensão emocional de sua vida. Em função disso, as empresas que adotaram os postulados da teoria tenderam a tornar mais informais as rígidas prescrições do taylorismo, ainda que não necessariamente introduzissem inovações de caráter técnico com tal objetivo.

Sob o neoliberalismo e a produção flexível as relações entre o processo produtivo e a subjetividade do trabalhador se alteram tendo em vista a adequação entre ambas. $O$ trabalho em equipe, a demanda por maior protagonismo e colaboração do trabalhador para o aprimoramento das atividades, por meio dos Círculos de Controle de Qualidade, a adoção do just in time e do kanban, a exaltação da polivalência, demandam a constituição de relações sociais e institucionais entre trabalho e capital de natureza diversa daquelas existentes sob o taylorismo. Todo esse conjunto de elementos conduz ao estabelecimento de novas formas de contratação e emprego que priorizam a mais valia relativa ao invés da absoluta a qual, por seu turno, coloca novas exigências de qualificações técnicas e comportamentais que afetam a subjetividade dos trabalhadores. 
Em um texto antigo $(X X X X X)$ considerei que as transformações nas relações entre capital e trabalho introduzidas pela produção flexível produzem o progressivo deslocamento da importância anteriormente atribuída à qualificação formal e ao saber técnico (...) como elementos centrais para a definição da identidade do trabalhador, de seu lugar social e de seu salário para outra dimensão, resumida na expressão "saber ser", na qual se confundem, articulam saberes, comportamentos, racionalidade orientada para fins que mobilizam intensamente a subjetividade do trabalhador, visando sua adesão às expectativas e objetivos da empresa. Todavia, não apenas isso mas, também, o que se torna cada vez mais patente, a valorização de uma sociabilidade que tende a expandir e a naturalizar o neoliberalismo como forma de ser no mundo contemporâneo, sob suas diversas formas.

Dardot e Laval (2016) apresentam elementos que, a meu ver, dão apoio a tal interpretação. Um deles diz respeito ao fato de que a concepção neoliberal do trabalho, no momento presente, se estrutura a partir da incerteza e do risco. Há certezas com relação à pouquíssima manutenção de empregos perenes e bem pagos e inúmeras incertezas quanto aos demais empregos disponíveis, sua forma e manutenção. Estabelece-se, portanto, o risco sempre constante do desemprego, do emprego parcial ou do trabalho aviltante e precarizado, dados os processos crescentes de desindustrialização e o crescimento relativo do trabalho no âmbito dos serviços os quais, como visto, assumem as mais diferentes formas e remunerações. Isto coloca para cada potencial aspirante a um emprego o desafio de obtê-lo na condição de trabalho estável e de mantê-lo. Dado o número elevado e crescente de desempregados, seja na indústria, seja nos serviços, e dado o fato de que as instituições que poderiam oferecer algum tipo de proteção e defesa de direitos do trabalho (os sindicatos e mesmo o Estado) não o fazem, instalase, no âmbito da sociedade como um todo, um ferrenho processo de disputa. Uma das consequências marcantes para a subjetividade do potencial trabalhador ou para a de quem já está empregado se refere à responsabilidade que passa a pesar sobre seus ombros no sentido de afirmar-se como capaz de disputar um emprego e de nele permanecer e ascender. Em consequência desenvolve-se, no plano social mais amplo, assim como no plano individual, a cultura da meritocracia, do individualismo e da competição que mina as perspectivas de valorização da vida coletiva. Em função dessa responsabilização os trabalhadores ou os que estão à procura de trabalho, são instados, de um lado, a se tornarem empregáveis (a cultura da empregabilidade), para o que a escola é frequentemente convocada e alçada erroneamente à condição de solução. De outro lado, são também instados a se tornarem empreendedores, transformandose em pequenos empresários ou, como dizem Dardot e Laval (2016), em "empresas de si" para se venderem como trabalhadores permanentes ou autônomos part time às empresas que terceirizam parcela de sua produção (geralmente na área de serviços), inclusive sob a forma de trabalhadores home office. ${ }^{12}$ Desse ponto de vista, a oposição entre trabalho e capital tende a desaparecer, assim como a observância dos direitos trabalhistas, pois, nessas circunstâncias o "trabalhador empresa" e a instituição que o emprega se defrontam e negociam entre si como empresas. ${ }^{13} \mathrm{O}$ sucesso ou insucesso na materialização desse tipo de solução tende a ser atribuído ao próprio trabalhador, desconsiderando-se as condições objetivas da vida econômica e social que o colocam nessa situação. Não por acaso, a resiliência ${ }^{14}$ é uma das denominadas "competências socioemocionais" mais cultuadas por empresários, agências de emprego, por escolas afinadas com as perspectivas do neoliberalismo e mesmo pelos próprios trabalhadores (ainda que possam desconhecê-la como tal).

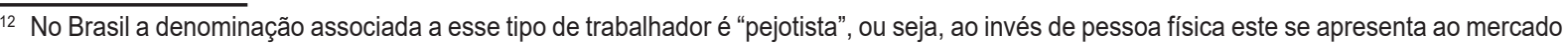
como pessoa jurídica (PJ).

${ }^{13}$ A reforma trabalhista aprovada pelo governo Temer e a MP 881 proposta por Bolsonaro alinham-se perfeitamente a esse figurino.

${ }^{14}$ A resiliência diz respeito à capacidade de pessoas resistirem à adversidade, valendo-se da experiência assim adquirida para construir novas habilidades e comportamentos que Ihes permitam sobrepor-se às condições adversas e alcançar melhor qualidade de vida. Está muito associada ao esforço, à competitividade e à meritocracia.
}

Cad. Pesq., São Luís, v. 26, n. 4, p. 60-72, out./dez. 2019. 


\section{Retornando ao princípio}

No que se refere às exigências do neoliberalismo relativas ao trabalhador seja da produção, seja dos serviços, a educação escolar no Brasil tem sido, há pelo menos duas décadas, instada a promover a formação de crianças e jovens para se situarem e atuarem nas sociedades capitalistas da atualidade de acordo com a sociabilidade que convém a tais demandas. O argumento principal é o de que é nessas sociedades que provavelmente viverão e trabalharão sendo, por isso, necessário não só adaptar-se a elas, mas cultivar os valores que as sustentam. As políticas de educação voltadas ao desenvolvimento de competências e habilidades servem a esse propósito. No caso brasileiro a última proposta nessa direção é constituída pela Base Nacional Comum Curricular, homologada em 2017 pelo Conselho Nacional de Educação (CNE), a qual visa promover formação durante toda a educação básica. É, pois, do nosso ponto de vista, uma proposta a ser questionada e, na medida do possível, desativada. Manifestações de instituições que congregam professores, técnicos em educação ou pesquisadores têm sido realizadas com esse objetivo desde 2013 quando os primeiros passos começaram a ser dados para a construção da BNCC. Tais manifestações precisam ser fortalecidas e multiplicadas. Até porque, há outras, de peso, em sentido contrário, envolvendo a associação entre organismos públicos e privados, inclusive estrangeiros. Fazer a crítica da BNCC e das políticas e práticas construídas à sua sombra constitui uma forma indireta de contribuir para a formação do trabalhador e para fortalecer a luta deste contra as diferentes formas de exploração identificadas anteriormente.

Numa perspectiva mais direta cabe defender outra proposta educacional, já existente, que se confronta com a anteriormente exposta. Ou seja, a de educação unitária, omnilateral proposta por Gramsci (1979), cujos objetivos não são apenas a formação em si (embora importante), mas o desenvolvimento de uma visão de mundo e de trabalho mais elaborada que se articule ao compromisso com a ação política expressa sob a forma de vontade coletiva em defesa de uma sociedade justa e igualitária e questionadora das formas de exploração do trabalho apontadas anteriormente.

Sem entrar no detalhamento dessa concepção, já explorada por mim em outros trabalhos (XXXXX; XXXXX) ressalto um de seus elementos principais: a de estruturarse tendo por base o trabalho como princípio educativo. Daí a proposição de Gramsci de que a escola se volte, de um lado, para o desenvolvimento das noções científicas que permitiriam não só a libertação das visões folclórica de mundo, mas também a clareza de que tais noções se desenvolveram respondendo à necessidade humana de defrontar-se com a natureza e, de outro, para as noções relativas à vida em sociedade, que é a forma pela qual os sujeitos trabalham, implicando a elaboração de normas e regras sociais, definição de direitos e deveres, enfim o conhecimento da vida social e suas determinações, mediada pelo trabalho.

Nessa perspectiva, a título de exemplo, pelo menos no ensino médio, levanto a possibilidade de que uma das formas de abordar o trabalho como princípio educativo possa se dar, tendo em vista o objeto da discussão que motivou este artigo, por meio do desenvolvimento da temática condição e exercício profissional de pais, familiares, amigos(as) e deles(as) próprios, alunos(as), ${ }^{15}$ tendo por referência a proposta avançada por Ramos (2005, p. 118-124) relativa à organização do currículo na perspectiva da formação integrada. O tema abrange várias questões interligadas (por exemplo, saúde, vida econômica, moradia, alimentação, consumo, transporte, cultura, vida social e, evidentemente, os diferentes trabalhos, realizados por meio das variadas práticas de pais e conhecidos, inclusive colegas), bem como variadas áreas do conhecimento (biologia, economia, sociologia, filosofia, matemática, português, história, etc.), incluindo disciplinas relativas à educação profissional, se houver a integração entre estas e as de formação geral, que poderiam ser estudadas individualmente ou articuladas entre si, de forma a conduzir a uma visão integrada sobre o fenômeno em pauta e, na medida do possível, sobre sua totalidade. Uma abordagem dessa natureza poderia

\footnotetext{
15 Por pais estou entendo pai e mãe.
} 
contribuir para que os jovens, por intermédio da interlocução entre eles e os professores e deles com os familiares e amigos passassem, como diz Gramsci, do "sentir", ou seja, da compreensão de senso-comum sobre sua vida e sobre os trabalhos que realizam, decorrentes dessa mesma vivência, para uma visão mais elaborada e articulada, ou de bom-senso, sobre ela, bem como de sua relação com o mundo em que essa vida transcorre. Isto pode ter efeito mais ou menos imediato sobre tais jovens, na medida em que vários deles atuam, ao mesmo tempo, como estudantes e como trabalhadores, ou estão aspirando, por necessidade, ao ingresso no mercado de trabalho. Pode, também, ter um efeito de mais longo prazo, considerando a possibilidade de que tal inserção venha a ser adiada.

Para ser efetivada uma proposta como essa se defronta, no momento presente, com várias questões em função de sua complexidade pedagógica. A primeira diz respeito ao preparo profissional dos professores para exercer as atividades concernentes a ela, bem como às condições precárias existentes para a realização de seu próprio trabalho, nessa perspectiva.

A segunda refere-se ao momento adverso vivido pelo país face ao governo instalado em 2018 que dá continuidade, de forma piorada, à gestão Temer, em especial, na área da educação. As poucas decisões tomadas recentemente nessa área dizem respeito ao ataque à própria educação, seja no plano de seus valores e objetivos, seja no plano econômico, com o corte de recursos financeiros a universidades e, recentemente (15/07/2019), à educação básica.

A terceira remete ao fato de que muito provavelmente estarão nas escolas públicas as crianças e jovens cujos familiares e amigos fazem parte de uma "classeque-vive-do-trabalho", heterogênea, dividida entre o compromisso e o individualismo, superexplorada, desempregada ou subempregada, sem representações que defendam seus direitos e desenvolvam algum tipo de formação e reflexão política.

Nesse contexto, os processos de formação do trabalhador, desencadeados pela própria forma como se organiza a produção, correm o risco de serem reificados e naturalizados não apenas pelos que têm interesse na submissão desse trabalhador, mas, também pela própria classe trabalhadora, seja pelas suas condições adversas de vida, seja por falta de informação e/ou de formação política. Contudo, esta questão, ao mesmo tempo em que representa uma dificuldade para o desenvolvimento da temática, é a razão de ser de sua proposição.

O conjunto das considerações anteriormente apresentadas não teve, obviamente, a intenção de diminuir o papel que a educação escolar desempenha no processo de formação do trabalhador, mas a de apontar para a complexidade inerente à formação desse sujeito social. O papel desempenhado pela escola é reconhecido tanto pelos que assumem sua defesa frente às condições adversas promovidas pelo neoliberalismo, quanto pelos que, aderentes a este, enxergam nela o instrumento para qualificar 0 trabalhador que lhes convém.

Todavia, as resistências ao atual estado de coisas não podem restringir-se, pareceme, ao plano das atividades pertinentes à educação escolar.

Harvey, a respeito de uma questão muito mais complexa do que a que está em discussão, qual seja, a da criação de possibilidades de promover um movimento anticapitalista, vai, parece-me, em direção semelhante, ao indicar que, para obter sucesso, este deve ter caráter unificado. Nas suas palavras:

um movimento político pode começar em qualquer lugar (nos processos de trabalho, em torno de concepções mentais, na relação com a natureza, nas relações sociais, na concepção de tecnologias e formas de organização revolucionárias, na vida diária ou nas tentativas de reformar as estruturas institucionais e administrativas, incluindo a reconfiguração do poder do Estado). O truque é manter o movimento político movendo-se de uma esfera de atividade para outra, de maneiras que se reforçam mutuamente. (HARVEY, 2011, p. 185) 
Nesse sentido é necessário, além de defender a formação de caráter unitário e omnilateral na perspectiva gramsciana, promover sua articulação com ações e organizações sociais que partilhem das mesmas preocupações, especialmente, no caso presente, aquelas mais diretamente ligadas ao trabalho e aos trabalhadores, considerando a concepção ampliada de Estado em Gramsci e as relações entre a sociedade civil e a sociedade política que a compõem, tendo em vista o papel que ambas desempenham na disputa por hegemonia.

\section{REFERÊNCIAS}

ANTUNES, R. Adeus ao trabalho?: ensaio sobre as metamorfoses e a centralidade do mundo do trabalho. 2ed. São Paulo: Cortez, 1995.

ANTUNES, R. Os sentidos do trabalho: ensaio sobre a afirmação e a negação do trabalho. São Paulo: Boitempo, 1999.

DARDOT, P.; LAVAL, C. A nova razão do mundo: ensaio sobre a sociedade neoliberal. Tradução de Maria Echalar. São Paulo: Boitempo, 2016.

FAGIANI, C. C.; PREVITALI, F. S. A nova configuração da classe trabalhadora no século XXI: qualificação e precarização. Disponível em htpps:rct.dieese.org.br/index.php/rct/article/ view/47. Acesso em 04/07/2019

GRAMSCI, A. Os intelectuais e a organização da cultura. 3. ed. Rio de Janeiro: Civilização Brasileira, 1979.

GRAMSCI, A. Maquiavel, a política e o estado moderno. 3. ed. Rio de Janeiro, Civilização Brasileira, 1978.

HARVEY, David. A condição pós-moderna. São Paulo: Loyola, 1992.

HARVEY, David. O enigma do capital: e as crises do capitalismo. São Paulo: Boitempo, 2011.

HOUAISS, A.; VILLAR, M. S. Dicionário Houaiss da Língua Portuguesa. Rio de Janeiro: Objetiva, 2001.

POCHMANN, M.; MORAES, R. Capitalismo, classe trabalhadora e luta política no início do século XXI: experiências no Brasil, Estados Unidos, Inglaterra e França. São Paulo: Fundação Perseu Abramo, 2017. Disponível em: https://fpabramo.org.br/.../capitalismo-classetrabalhadora-e-luta-política-no-início-do-seculo-XXI. Acesso em 20/06/2019

RAMOS, M. Possibilidades e desafios na organização curricular. In: FRIGOTTO, G.; CIAVATTA, M.; RAMOS, M. (Orgs.) Ensino médio integrado: concepção e contradições. São Paulo: Cortez, 2005. 